\title{
PAISAGEM, ESTUDO DE CASO NO ESPAÇO AGRÁRIO DO NOROESTE DO PARANÁ
}

landscape, study in the agricultural area of the northwest Paraná

\author{
Elpídio Serra ${ }^{1}$ \\ Maria Teresa de Nóbrega ${ }^{2}$ \\ José Antonio de Andrade ${ }^{3}$ \\ $a a a_{a}$
}

\begin{abstract}
Resumo
O espaço agrário do Noroeste do Paraná é bastante dinâmico e embora sendo de ocupação recente já passou por uma série de transformações, a maior parte delas para atender às demandas do mercado externo. Por conta desse dinamismo, no presente trabalho é utilizado como espaço de referência para estudos e aplicativos do termo paisagem. Num primeiro momento, o trabalho apresenta algumas reflexões sobre paisagem; em seguida procura associar o conceito à realidade agrária do Noroeste do Paraná e do município de Floraí. A preocupação é evidenciar que a paisagem não é estática, ela se apresenta em constante movimento, comportamento que se encaixa na dinâmica da ocupação e do uso econômico da terra agrícola do Noroeste do Paraná, o que justifica o fato da região e de um de seus municípios serem tomados como exemplos do estudo aplicativo.
\end{abstract}

Palavras-chave: Paisagem agrária, Noroeste do Paraná, Dinâmica regional.

\begin{abstract}
The agricultural area of the Northwest Paraná is quite dynamic and although it is from of recent occupation it has gone through a series of transformations, most of them to meet the demands of foreign markets. Because of that dynamism, this work uses the space as a reference area for studies and applications of the term landscape in this work. At first, the paper presents some reflections on landscape and then tries to associate the concept to reality land Northwest of Paraná and the city of Floraí. The main issue is to show that the landscape is not static, it presents itself in constant motion, a behavior that fits the dynamics of occupation and economic use of agricultural land in the Northwest Paraná, which justifies the fact of the region and one of his municipalities are taken as examples of the study application.
\end{abstract}

Key words: Agrarian landscape, Northwest Paraná, Regional dynamics.

\begin{abstract}
Resumen
La superficie agrícola del noroeste de Paraná es muy dinámico y aunque sea de reciente ocupación ha pasado por una serie de transformaciones, en su mayoría para satisfacer las demandas de los mercados extranjeros. Debido a este dinamismo, este trabajo utiliza el espacio de referencia para los estudios y aplicaciones del término paisaje. En un primer momento, el trabajopresenta algunas reflexiones sobre el paisaje y luego trata de asociar el concepto de la realidad agraria del noroeste de Paraná y de la ciudad de Floraí. La preocupación es mostrar que el paisaje no es estático, se presenta en constante movimiento, con comportamiento que se ajusta a la dinámica de ocupación y el aprovechamiento económico de las tierras agrícolas en el noroeste de Paraná, lo que justifica el hecho de la región y uno de sus municipios son tomados como ejemplos de la aplicación del estudio.
\end{abstract}

Palabras clave: Paisaje agrário, Noroeste de Paraná, Dinámica regional.

(1) Prof. Dr. do Programa de Pós-Graduação em Geografia da Universidade Estadual de Maringá - Av. Colombo, 5790. CEP 87020-900, Maringá (PR), Brasil, Tel.: (+ 55 44) 30114731 - serraelpidio@gmail.com

(2) Prof ${ }^{a}$. Dra . do Programa de Pós-Graduação em Geografia da Universidade Estadual de Maringá - Av. Colombo, 5790. CEP 87020-900, Maringá (PR), Brasil, Tel.: (+55 44) 30114731 - mtnobrega@uol.com.br

(3) Msc. pelo Programa de Pós-Graduação em Geografia da Universidade Estadual de Maringá - Av. Colombo, 5790. CEP 87020-900, Maringá (PR), Brasil, Tel.: (+55 44) 30114731 - andrade_pr@hotmail.com

\section{aaAaa}

Revista da ANPEGE, v. 8, n. 10, p. 85-99, ago./dez. 2012.

ISSN 1679-768 X @ $\odot 2003$, Associação Nacional de Pesquisa e Pós-Graduação em Geografia. Todos os direitos reservados. 


\section{INTRODUÇÃO}

A partir da afirmativa de Milton Santos (2004) de que "a paisagem é o conjunto de formas que, num dado momento, exprimem as heranças que representam as sucessivas relações localizadas entre homem e natureza", é que o presente trabalho foi desenvolvido, tendo por base aplicativa para efeito de coleta de dados a mesorregião Noroeste do Paraná e, dentro dela, o município de Floraí. Na prática, trata-se de um espaço observado e interpretado como paisagem em duas escalas: a local e a regional.

As "heranças que representam as sucessivas relações localizadas entre homem e natureza", vão corresponder, no desenvolvimento do trabalho, aos fatos e situações que marcaram a história da ocupação local e regional. Como a abordagem vai ficar restrita ao enfoque agrário, a paisagem que será discutida é a paisagem rural.

Num primeiro momento, é resgatada a importância das lavouras de café, como herança histórica que impulsionou a economia e o processo de ocupação dos dois espaços tomados como referência para o estudo de paisagem. As lavouras de café, associadas à fixação do homem no campo, e à estrutura criada em função das necessidades de moradia e de subsistência, vão constituir as heranças que, no decorrer dos tempos, passam por sucessivas modificações, provocadas pelo mercado de produtos agrícolas. As relações com o mercado em função do café, as relações de consumo interno em função das lavouras de subsistência, os espaços de moradia e de produção e toda a estrutura necessária, vão compor o mosaico da primeira paisagem nas dimensões local e regional. Com a crise do café durante os anos 1960 e a destruição das lavouras pelas geadas ocorridas em 1975, esta paisagem original praticamente desaparece, dando lugar a outra bem diferente que, por sua vez, sofre novas modificações, sempre em função dos apelos dos mercados de produtos agrícolas, o interno e o externo. Na nova paisagem, comandada pelas lavouras de mercado, o campo, que era espaço de produção e de moradia, se transforma apenas em espaço de produção: o homem é expulso para as cidades, ocorrendo o fenômeno do êxodo rural. Mas mesmo como espaço exclusivo de produção, as modificações acontecem, frise-se, comandadas pelos mercados.

No lugar do café, surgem as lavouras mecanizadas nos solos oriundos do basalto e as pastagens plantadas nos solos derivados do arenito da Formação Caiuá, isto logo após as geadas que destruíram as lavouras de café. Na virada do século e do milênio, são as lavouras de cana que ganham destaque, capitaneadas pela instalação de usinas de álcool na região. Tanto uma como outra forma de uso do solo que vão suceder o café, vão apresentar algumas características em comum, sendo as principais, o esvaziamento do campo, a concentração fundiária e a atividade agrícola praticada como atividade empresarial.

Essas transformações representam um enfoque do trabalho, no sentido de demonstrar que a paisagem, no caso do espaço regional e do espaço local, é muito dinâmica. Outro enfoque é provocar reflexões em torno do termo paisagem. Com base em contribuições de diversos autores, o termo é discutido e aplicado como uma categoria de análise capaz de refletir a síntese das relações entre sociedade e natureza, que produzem o espaço geográfico. No caso da aplicação no município de Floraí, análise se inicia com o reconhecimento das unidades de paisagem no território municipal.

\section{PAISAGEM: O CONCEITO E SUA EVOLUÇÃO}

O termo paisagem, como representativo de um conjunto de relações interativas entre elementos da natureza e da sociedade, foi pela primeira vez utilizado pela Geografia no século XIX, por iniciativa do geógrafo alemão Alexander Von Humboldt. A expressão "o caráter total de uma área geográfica" representou a definição de Humboldt para paisagem. Sem negligenciar os aspectos humanos, mas valorizando os aspectos físicos, o que pode ser justificado diante do fato de que 
Humbold era um geógrafo físico, através da paisagem, ele procurou conhecer e explorar as interrelações entre os seus componentes, no sentido de entendê-la como um "organismo vivo". A partir da contribuição de Humbold, a paisagem, juntamente com os termos região, meio e espaço, passa a ser importante ferramenta dos trabalhos desenvolvidos pela Geografia, particularmente a Geografia Agrária, e novos significados acabaram sendo atribuídos ao termo, mas sem um expressivo distanciamento do conceito inicial.

Ainda como contribuição da geografia alemã, entre os séculos XVIII e XIX, o termo adquire o poder de síntese, tendo por base a concepção de Landschaft (paisagem). Segundo Diniz (1986),

A ideia de Landschaft, complexa e mesmo ambígua, parte do pressuposto de que a natureza do mundo pode ser concebida como evento visual, total e unido. Essa ideia liga a ciência e à arte, fato comum no século XVIII, baseado na concepção aristotélica de que a natureza ou o absoluto se abre por si mesmo à observação e nada pode ser encontrado além dos fenômenos visíveis. Consequentemente, uma geografia baseada nessa concepção dá à observação da paisagem, natural ou transformada pelo homem, uma posição central. (DINIZ,1986, p.14)

No mesmo século XIX, a expressão passa a ser entendida, na Geografia, como o conjunto de formas que caracterizam um determinado setor da superfície terrestre (BOLÓS, 1992). No século XX, particularmente entre as décadas de 1940 e 1950, o homem passa a entender e a se posicionar, ele próprio, como um componente da paisagem; a partir daí, se populariza a ideia de que a paisagem precisa ser conservada e preservada como um bem da sociedade. Em meio às complexidades geradas na aplicação e na interpretação do termo, o geógrafo Milton Santos (2004) tratou de esclarecer que existem diferenças nos significados de paisagem e de espaço. "Paisagem e espaço não são sinônimos", afirmou, explicando em seguida os respectivos significados.

A paisagem é o conjunto de formas que, num dado momento, exprimem as heranças que representam as sucessivas relações localizadas entre homem e natureza. O espaço são essas formas mais a vida que as anima (SANTOS, 2004, p. 103)

Na década de 1960, os estudos da paisagem sofrem um grande avanço com a incorporação do conceito de geossistema aos paradigmas da Geografia. Segundo SOTCHAVA (1962), geossistema pode ser entendido como uma classe peculiar dos sistemas dinâmicos abertos e hierarquicamente organizados. $\mathrm{O}$ autor considera a terra o ambiente geográfico, ou geossistema planetário, que se divide em inúmeros domínios, por sua vez constituídos de componentes naturais (relevo, clima, solos, águas superficiais e subsuperficiais, as comunidades vegetais e animais), e que se mantêm numa interação complexa, como um sistema aberto. Na interpretação de MELO (1995), geossistema constitui algo real, objetivo, podendo ser reconhecido como formas geográficas da matéria em movimento, regidas por leis naturais e pela compreensão de sua estrutura e as manifestações sistêmicas de sua funcionalidade.

Para explicar o significado de geossistema, CHRISTOFOLETTI (1995) se utiliza das expressões organização espacial, sistema e fluxos, associadas à expressão mosaico paisagístico, designativa de paisagem. Segundo ele,

Os geossistemas representam a organização espacial resultante da interação dos elementos componentes físicos da natureza, possuindo expressão espacial na superfície terrestre e representando uma organização (sistema) composta por elementos, funcionando através de fluxos de energia e matéria. As combinações de massa e energia, no amplo controle energético ambiental poderão criar heterogeneidades internas no geossistema, expressando-se em mosaico paisagístico. Há os fluxos na dimensão horizontal conectando as diversas combinações paisagísticas internas. Independentemente da ação e presença humana, a natureza físico-biológica do sistema terrestre organiza-se ao nível dos ecossistemas e geossistema. (CHRISTOFOLETTI, 1995) 
As concepções de paisagem e geossistema muitas vezes são confundidas entre si, sobretudo pela ênfase dada à integração dinâmica dos seus componentes. Entretanto deve-se enfatizar que a primeira, a paisagem, corresponde a uma categoria de análise da geografia, e o segundo, o geossistema, é assumido como um modelo aplicado aos estudos de paisagem (BOLÓS, 1992). O presente trabalho se apóia nessas concepções, empregando a concepção de paisagem para detectar a diversidade e evolução da organização espacial no território municipal de Floraí e a abordagem sistêmica para o reconhecimento das suas estruturas e funcionamento.

Os espaços tomados como referência, no contexto do presente trabalho, são a mesorregião Noroeste do Paraná e, dentro dela, o município de Floraí, localizado na bacia hidrográfica do vale do rio Ivaí. A proposta é, através do processo histórico envolvendo a ocupação humana e o uso econômico da terra agrícola, evidenciar a dinâmica da paisagem nas escalas regional e local.

\section{A DINÂMICA DA PAISAGEM NO NOROESTE DO PARANÁ}

No meio rural, considerando as sucessivas intervenções dos produtores, proprietários ou não, no sentido de extraírem da terra o máximo rendimento da atividade agrícola, a paisagem é construída, modificada, adaptada, enfim sofre todos os ajustes possíveis tendo em vista, sempre, metas estabelecidas em termos de produção e de produtividade. Extrair da terra o seu máximo sintetiza, no espaço rural, a evolução e transformação da paisagem.

Para exemplificar essa transformação da paisagem movida, de um lado por modificações no espaço agrário e, de outro lado pela dinâmica do mercado, principalmente de commodities agrícolas, a mesorregião Noroeste do Paraná pode ser tomada como referência. Colonizado entre os anos 1940 e 1960, o noroeste paranaense sofreu uma série de transformações, que continuam ocorrendo, sempre por pressões atreladas aos interesses do mercado.

A mesorregião, como parte integrante da região Norte do Paraná, teve na Companhia de Terras Norte do Paraná e na sua sucessora Companhia Melhoramentos Norte do Paraná sua principal colonizadora. A empresa adquiriu do governo do Estado, na virada do século XIX para o século XX extensa área de terras, área esta ampliada com nova aquisição por volta dos anos 40 do século $\mathrm{XX}$. No total, foram transferidos do Estado para a empresa, um milhão e trezentos mil hectares, totalmente destinados à colonização.

A Companhia de Terras iniciou o loteamento na década de 1930 para concluir 30 anos depois, nos anos 1960. Primeiramente, a colonização foi concretizada no vale do rio Tibagi, tendo Londrina como cidade polo. Em seguida, a marcha colonizadora foi deslocada para o Vale do rio Ivaí, tendo Maringá como eixo polarizador. Por último, foi deslocada no sentido do vale do rio Piquirí, tendo como eixos polarizadores os municípios de Cianorte e Umuarama. A colonização, portanto, se desenvolveu em três momentos distintos, incorporando, em sequência, as porções do espaço regional denominadas Norte Velho, Norte Novo e Norte Novíssimo. A porção denominada Norte Novíssimo fez parte da última aquisição de terras efetivada pela Companhia junto ao Governo do Estado e, na sua extensão geográfica, coincide com o domínio geográfico da mesorregião Noroeste.

A colonização, toda ela, foi impulsionada pelo deslocamento das lavouras de café, do Oeste paulista para o Norte do Paraná. Como as condições do solo e do clima da extensa área adquirida pela loteadora eram favoráveis à cultura cafeeira e como os preços praticados no mercado externo eram compensadores, a Companhia não teve dificuldades na comercialização dos lotes rurais. Para atender as condições dos compradores, a estrutura fundiária foi montada privilegiando lotes de pequena e média dimensão, variando entre 10 e 20 hectares, principalmente. Mesmo sendo em pequenas dimensões, os lotes eram vendidos a prazo, com pagamentos que venciam ano a ano, sempre coincidindo com o período de comercialização das safras, o que contribuiu para evitar a inadimplência dos compradores.

Nos anos 1940, a Companhia de Terras Norte do Paraná, de capital inglês, que iniciou o loteamento e que negociou a compra da extensa área junto ao Governo do Paraná foi vendida a 
um grupo de empresários brasileiros, surgindo aí sua sucessora Companhia Melhoramentos Norte do Paraná. A nova empresa não modificou em nada as estratégias adotadas pela CTNP no que se refere à divisão e comercialização dos lotes, bem como no que se refere à localização e função das cidades implantadas.

A Companhia de Terras Norte do Paraná adotou diretrizes bem definidas. As cidades destinadas a se tornarem núcleos econômicos de maior importância seriam demarcadas de cem em cem quilômetros, aproximadamente. Entre estas, distanciadas de 10 a 15 quilômetros, seriam fundados os patrimônios, centros comerciais e abastecedores intermediários. Tanto nas cidades como nos patrimônios a área urbana apresentaria uma divisão em datas comerciais e residenciais. Ao redor das áreas urbanas se situariam cinturões verdes, isto é, uma faixa dividida em chácaras que pudessem servir para a produção de gêneros alimentícios para o consumo local, como aves, ovos, frutas, hortaliças e legumes. A área rural seria cortada de estradas vicinais, aberta de preferência ao longo dos espigões, de maneira a permitir a divisão da terra da seguinte maneira: pequenos lotes de 10,15 ou 20 alqueires, com frente para a estrada de acesso e fundos para um ribeirão. Na parte alta, apropriada para plantio de café, o proprietário da gleba desenvolveria sua atividade agrícola básica: cerca de 1.500 pés por alqueire. $\mathrm{Na}$ parte baixa construiria sua casa, plantaria sua horta, criaria os seus animais para consumo próprio, formaria seu pequeno pomar. (CMNP, 1975, p. 76)

A colonização e os atos dela resultantes, caso da retirada da vegetação nativa, da fixação dos moradores e do desenvolvimento de atividades agrícolas, vai constituir, no Noroeste paranaense, a primeira fase da transformação da paisagem regional. Em outro sentido, vai ser inaugurada através desse processo inicial, a primeira paisagem construída pelo homem, ocupando o lugar da paisagem natural, a que até o momento não havia sofrido qualquer forma de intervenção ou interferência humana.

O primeiro contato do homem com o ambiente natural constrói um tipo de paisagem que, no entanto, não é duradouro. Relatos de pioneiros 2 adiantam que a estrutura inicial construída no lote tinha caráter provisório, que deveria suportar, no máximo até as primeiras colheitas de café, quando deveriam ser substituídas por construções mais resistentes. A esta altura o agricultor, já com algum capital disponível, poderia pensar em moradia coberta de telhas de barro e com paredes mata juntadas, no lugar das casas ou barracos cobertos de sape ou de tabuinhas. Significa isso que a primeira paisagem, no curto prazo sofre modificações que, por sua vez, vão passar por outras modificações no decorrer do tempo, na medida em o morador vai se estabilizando e na medida em que o mercado passa a exigir novos produtos agrícolas. A paisagem se transforma em resposta à sucessão de mudanças, mas refém de fatores externos, no caso tendo o mercado como destaque. Significa isso que quanto mais exigente for o mercado, tanto em termos de quantidade como em termos de qualidade de produtos agrícolas, mais dinâmica acaba se tornando a paisagem rural.

No Noroeste do Paraná, seguindo o projeto de colonização das empresas loteadoras, a paisagem inicial refletia a estrutura fundiária projetada, constituída, basicamente, de lotes de pequena e média dimensão (variando entre 10 e 20 hectares), tendo, nesses lotes, as casas dos proprietários e seus empregados (geralmente trabalhadores fixos), uma lavoura de mercado localizada nos espigões, a parte alta da propriedade onde o risco de geadas era menor, e lavouras de subsistência nos demais espaços da propriedade, incluindo as entrelinhas das lavouras de mercado. Como as lavouras de subsistência deveriam garantir todo o suprimento alimentar das famílias que habitavam o lote, eram bastante diversificadas e na maioria dos casos dependiam de uma estrutura própria em termos de construções. Assim, além dos roçados de milho, arroz e feijão, das verduras e hortaliças, do gado leiteiro, dos porcos e das galinhas, a propriedade deveria dispor de galinheiro, chiqueiro, cocheira, paiol, horta e outras construções associadas ao manejo ou ao armazenamento dos produtos de subsistência. 
Essa paisagem inicial se mantém na região, mas sempre sofrendo pequenas alterações ou ajustes, até a crise do café, ocorrida nos anos 1960. Ela foi construída em função do café, para garantir a prosperidade do cafeicultor e a sua sobrevivência no próprio lote, onde se fixou com sua família e seus empregados. Com a crise do café e a necessidade de sua substituição por outros produtos agrícolas, deixou de ter sentido ou importância a manutenção dos componentes dessa primeira paisagem, da forma como construídos e localizados no interior do lote. E aí novas paisagens passam a ser construídas e territorializadas em função das necessidades e das características dos novos produtos que sucedem ao café como base da economia agrícola.

Depois do café, vieram as lavouras mecanizadas de soja, trigo e milho, que dominaram as áreas com solos derivados do basalto, popularmente designados de terra roxa e as pastagens plantadas, tendo em vista principalmente a pecuária de corte, ocuparam as áreas de solos arenosos oriundos do arenito da Formação Caiuá. Cada uma dessas formas de uso da terra "criou" uma paisagem com características próprias que, no entanto, apresentaram alguns pontos comuns entre si. Exemplos: ambas geraram profundas mudanças na estrutura fundiária e ambas provocaram o esvaziamento do campo e a consequente destruição de toda a estrutura dos lotes construída em função das lavouras de café e das lavouras de subsistência. O espaço de morada e de produção, que era antes, foi transformado apenas em espaço de produção. A lavoura diversificada, que existia, cedeu espaço para a cultura especializada. Para viabilizar a mudança, o homem foi expulso do campo, forçado a se deslocar para o espaço urbano, gerando o fenômeno do êxodo rural. Paralelamente, a pequena propriedade, que teve seus dias de glória com as lavouras de café e que foi a base da colonização regional, entrou em processo de desaparecimento para viabilizar propriedades maiores. Isso considerando que para viabilizar a mecanização das atividades agrícolas tornou-se necessária a concentração fundiária, o que significou anular, passar uma borracha em cima do modelo colonizador desenhado pelas empresas loteadoras.

A nova paisagem que surgiu, nada comparável à anterior, também passa por modificações, acompanhando o ritmo apressado da economia regional. Praticamente na virada do século XX para o século XXI, em função do processo de se buscar fontes energéticas alternativas ao petróleo para uso automotivo, as lavouras de cana-de-açúcar penetram na região e passam a disputar espaço com as pastagens plantadas e com as lavouras mecanizadas. Usinas de álcool são instaladas na região, o que vai intensificar o avanço das lavouras de cana que incorporam num primeiro momento as áreas de predomínio dos solos de textura arenosa e média, desenvolvidos a partir da Formação Caiuá; em seguida avançam sobre a zona de contato, onde os solos apresentam teores de argila mais elevados (vulgarmente denominados "terra mista"); por último atingem os chamados solos nobres, sobre os basaltos, argilosos, desalojando parte das lavouras mecanizadas.

Como consequência do avanço das lavouras de cana, a paisagem regional, que até os anos 1970 tinha no café sua atividade econômica predominante, associada às lavouras de subsistência; que dos anos 1970 aos anos 1990 o lugar do café foi ocupado pelas lavouras mecanizadas e pelas pastagens plantadas; dos anos 1990 em diante a disputa pelos espaços de produção ocorrem entre lavouras mecanizadas, pastagens plantadas e lavouras de cana. $\mathrm{O}$ avanço de uma forma de uso da terra e o consequente recuo de outra forma de uso passa a depender do comportamento do mercado, principalmente de commodities agrícolas. Uma grande diferença separa a paisagem "construída" nos tempos do café da paisagem "construída" nos tempos das novas lavouras. Nos tempos do café, o homem habitava o espaço rural em pequenas propriedades e tirava da terra, com a força do próprio trabalho, sua base de sustentação econômica e sua base de sobrevivência. Nos tempos das novas lavouras, o homem é forçado a abandonar o campo como espaço de moradia e de sobrevivência, ocorrendo o êxodo rural e a urbanização forçada; é destruída toda a estrutura dos lotes, em termos de construções para moradia e estocagem de produtos; as lavouras especializadas cobrem toda a dimensão do lote, da estrada ao fundo do vale; ocorre a concentração fundiária e o desaparecimento de milhares de pequenas propriedades; novas relações de trabalho e de produção 
(o arrendamento de terras, por exemplo) surgem no lugar das anteriores (o trabalho em parceria e o sistema de colonato, por exemplo).

\section{MUNICÍPIO DE FLORAÍ: PAISAGEM, TERRITÓRIO, ESPAÇO}

A sucessão de formas e características da paisagem, produzidas ou provocadas por agentes externos vai, portanto, transformar o Norte do Paraná e, particularmente a sua porção noroeste, num espaço ideal para se estudar os conceitos e aplicações desse importante paradigma da ciência geográfica. O estudo da paisagem, acoplado ao estudo de uma unidade regional, é que vai sustentar a sequência do presente trabalho, tendo como principal referência o município de Floraí. A escolha desse município deve-se ao fato de que ali se processaram todas as fases da dinâmica agrícola regional, das lavouras de café às lavouras de cana e ao fato de que apesar das transformações muitos antigos proprietários não se deslocaram para centros maiores: permaneceram no próprio município, embora residindo nos espaços urbanos e continuam donos da terra, embora arrendadas para as usinas de álcool ou grandes produtores de grãos. Segundo Andrade (2005),

Até a década de 1940, os sistemas naturais do município de Floraí estavam sujeitos a poucas interferências antrópicas. Com a colonização do Norte/Noroeste paranaenses, intensificaram-se as transformações destes sistemas naturais. As paisagens, regidas até então principalmente pela dinâmica natural, passaram a evoluir sob a imposição de uma nova dinâmica, tendo o homem como explorador dos recursos naturais e agente transformador da paisagem. (ANDRADE, 2005, p. 34)

Os primeiros contatos dos compradores de lotes com a área adquirida já denunciavam mudanças no sistema natural, tendo em vista a sua adaptação a formas de cultivo, no caso as lavouras de café. Para o plantio do café, produto que deveria gerar renda, no mínimo para o pagamento das prestações do lote junto à empresa loteadora, era necessário a destruição de toda a mata nativa. Andrade (2005) explica como foi esse processo em Floraí:

Após a derrubada, ateava-se fogo quando os galhos e folhas caídas já estavam secos, sendo necessário depois da queimada fazer a "descoivara", um trabalho árduo e estafante, que consistia em amontoar em leiras as galhadas. Depois deste trabalho os agricultores preparavam as covas e semeavam o café, normalmente de sete a oito sementes por cova, com espaçamento de $18 \times 18$ palmos, a uma profundidade de $40 \mathrm{~cm}$. As sementes começavam a germinar aos 60 dias após a semeadura e deste período coincidia com a época mais quente do ano, tornando-se necessário fazer a cobertura da planta jovem com lascas de madeira retiradas dos troncos das árvores caídas. (ANDRADE, 2005, p. 38)

A derrubada da mata nativa e os primeiros plantios de café marcam a construção ou constituição da primeira paisagem local e regional. Em Floraí, esse processo tem 1951 como ano de referência: foi quando a mata nativa sofreu sua mais intensa marca de destruição e quando as primeiras sementes de café foram sepultadas no solo. A partir dessa data, e por três décadas seguidas, praticamente tudo girou em torno do café no município. A dinâmica populacional pode ser considerada parâmetro da importância do café para a economia local, considerando o produto como forte gerador de empregos, basicamente no espaço rural. Em 1960, a população estimada era de 8 mil moradores, segundo dados da Prefeitura Municipal. Em 1970, segundo o Recenseamento Demográfico do IBGE, a população atingiu 11.050 habitantes e em 1975, segundo a mesma fonte, chegou a 17 mil. Essa foi a maior marca porque 1975 também foi o ano da grande geada que destruiu as lavouras do Paraná, e inaugurou a escalada regressiva da população. A geada de 1975 representou o golpe de misericórdia da cafeicultura regional e o efeito em Floraí, no aspecto populacional, foi configurado por uma sensível redução no número de moradores. O Recenseamento Demográfico de 1980 acusou uma população de 6.638 pessoas, menos da metade da contagem estimada pelo IBGE em 1975. Começa a erradicação dos cafeeiros queimados pela geada, seguida da formação de novas 
lavouras que surgem em lugar do café, dando início à nova paisagem acompanhada pelo constante esvaziamento populacional. Em 1990 a população caiu para 5.478 habitantes, em 2000 para 5.280 e no Recenseamento de 2010 era de apenas 5.037 habitantes.

O declínio populacional do município segue a lógica regional: a população do campo migra para as cidades e em seguida, das cidades menores para as maiores. A zona rural perde moradores para a zona urbana porque as novas atividades agrícolas, altamente dependentes da mecanização, são menos dependentes do fator trabalho; as cidades menores perdem habitantes para as cidades maiores porque não têm mercado de trabalho à altura do número de desempregados. Sem trabalho na cidade mais próxima, os trabalhadores se deslocam para cidades maiores, ou para outros Estados, onde as possibilidades de arrumar emprego são viáveis. Dentro dessa mesma lógica, ou em consequência dela, o Paraná, que até os anos 1960 era considerado o maior polo de atração populacional do Brasil, atingindo um crescimento médio de $6 \%$ ao ano (observando-se que isoladamente a região Norte, em função das oportunidades de trabalho geradas pelo café crescia mais de 10\% ao ano), passa a partir daí a ser considerado o maior polo dispersor. Nos anos 1980, o crescimento não atingiu a casa do $1 \%$ (medido pelo IBGE em $0,74 \%$ ), justificando medidas de intervenção do Estado para reter pelo menos parte da população migrante. A implantação de Vilas Rurais foi uma das medidas adotadas.

A princípio, as lavouras mecanizadas de soja, trigo e milho ocuparam o lugar das lavouras de café nos solos mais férteis do município, aqueles originados do basalto, enquanto que nos solos originados do arenito o lugar do café foi ocupado por outras atividades, com destaque para a pecuária de corte e de leite, a sericicultura, a suinocultura e lavouras de arroz e feijão. Pouco tempo depois, com o apoio de duas cooperativas (a COCAMAR e a INTEGRADA), as lavouras de soja incorporam áreas do arenito, o que significou o recuo das lavouras que haviam se instalado nesses espaços. Dados do EMATER, unidade de Floraí, indicam que nos anos agrícolas de 2003 e 2004, a soja atingiu uma área de cultivo de 12 mil hectares, já incorporando parte da área sobre o arenito, o que corresponde a um incremento de praticamente $30 \%$ em relação à área plantada nos anos agrícolas de 1998 e 1999. (EMATER, 2004).

A dinâmica da paisagem vai sofrer novas alterações no início dos anos 1990, quando as lavouras de cana-de-açúcar passam a concorrer com as lavouras mecanizadas e com as pastagens plantadas no município. Floraí não possui usina de açúcar e álcool instalada em seu espaço geográfico, mas as lavouras de cana passaram a ser cultivadas para atender a demanda de três usinas instaladas em municípios próximos: Maringá, São Carlos do Ivaí e Cidade Gaúcha. No ano agrícola 1995/96, os canaviais já respondem por $11 \%$ do valor total da safra de Floraí e no ano seguinte - 1996/97 - já respondem por $16 \%$, (EMATER, 2004).

\section{ASPECTOS FÍSICOS DA PAISAGEM}

O município de Floraí, cuja sede está situada a $23^{\circ} 19^{\prime} 00^{\prime}$ S e $52^{\circ} 17^{\prime} 00^{\prime}$ ' W, ocupa, em extensão territorial, uma área de $191,3 \mathrm{~km}^{2}$. Está sob o domínio do Clima Subtropical Úmido (Cfa), que se caracteriza por verões quentes e por invernos com geadas pouco frequentes. Estende-se por um setor do Terceiro Planalto Paranaense, compreendendo áreas de duas subunidades morfoesculturais: Planalto de Campo Mourão e Planalto de Umuarama (MINEROPAR, 2006a), aqui drenadas por afluentes do rio Ivaí.

Do ponto de vista geológico, o município está assentado sobre uma zona de contato entre duas formações geológicas, a Formação Serra Geral (rochas vulcânicas - basalto) e a Formação Caiuá (arenito) - Figura 1.

A Formação Caiuá é de idade cretácica e recobre a Formação Serra Geral. É constituída por arenitos de granulometria fina a média, de cores arroxeadas, e apresenta estratificação cruzada de grande porte (CPTI, 2000; MINEROPAR, 2006b). 
$\mathrm{O}$ arenito ocorre nas áreas topograficamente mais elevadas do município, geralmente acima de 350 metros e no máximo 560 metros de altitude, o que corresponde aos topos e altas vertentes dos interflúvios, enquanto o basalto é exposto a partir do terço inferior das vertentes e nos fundos de vales. No setor centro-sul do território municipal, onde as altitudes são em geral inferiores aos 350 metros, o basalto aparece como substrato de forma generalizada, desde os topos até os fundos dos vales. Em alguns locais, entretanto, a rocha vulcânica está recoberta por uma fina camada de depósitos sedimentares arenosos a areno-argilosos, de origem coluvionar, como é possível observar na Figura 1.

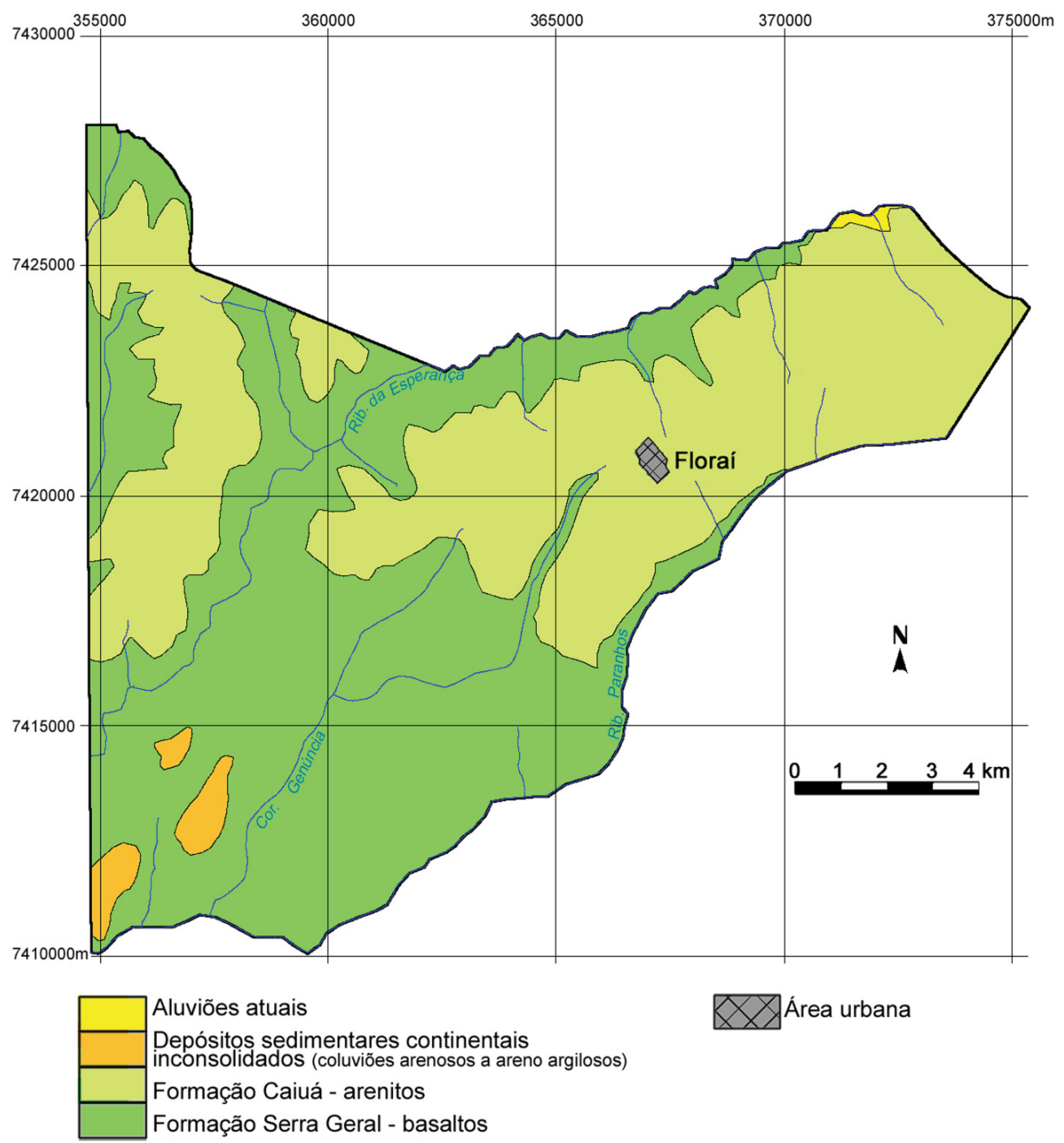

Figura 1 - Mapa geológico do município de Floraí (adaptado de MINEROPAR, 2006b)

Nos setores dominados pela Formação Caiuá e pertencentes à subunidade Planalto de Umuarama o relevo mostra-se mais dissecado, caracterizado por uma morfologia de colinas médias a pequenas, com topos arredondados, relativamente estreitos, e vertentes convexo-retilíneas algumas vezes interrompidas por rupturas e/ou pequenos patamares que marcam a passagem do arenito para o basalto. As declividades são predominantemente muito fracas ( 0 a $6 \%)$ no topo e fracas $(0$ a $12 \%)$ ao longo das vertentes. Vários tributários de primeira ordem entalham esses interflúvios gerando localmente, mesmo em posições de alta e média vertente, declividades mais acentuadas (12 a 20\%) que geralmente estão associadas à modelagem de patamares. Na porção centro-sul, área topograficamente mais baixa (altitudes que variam entre 250 e $350 \mathrm{~m}$ ) e de ocorrência principal das rochas basálticas, 
parte da subunidade Planalto de Campo Mourão, a morfologia é caracterizada por colinas amplas de topos largos e achatados, com vertentes convexo-retilíneas longas, cujas declividades são muito fracas ( 0 a $6 \%)$, mas que se acentuam ligeiramente nos setores de baixa vertente, onde variam de 6 a 12\% e, ocasionalmente, mas de modo restrito, de 12 a 20\% (Figura 2).

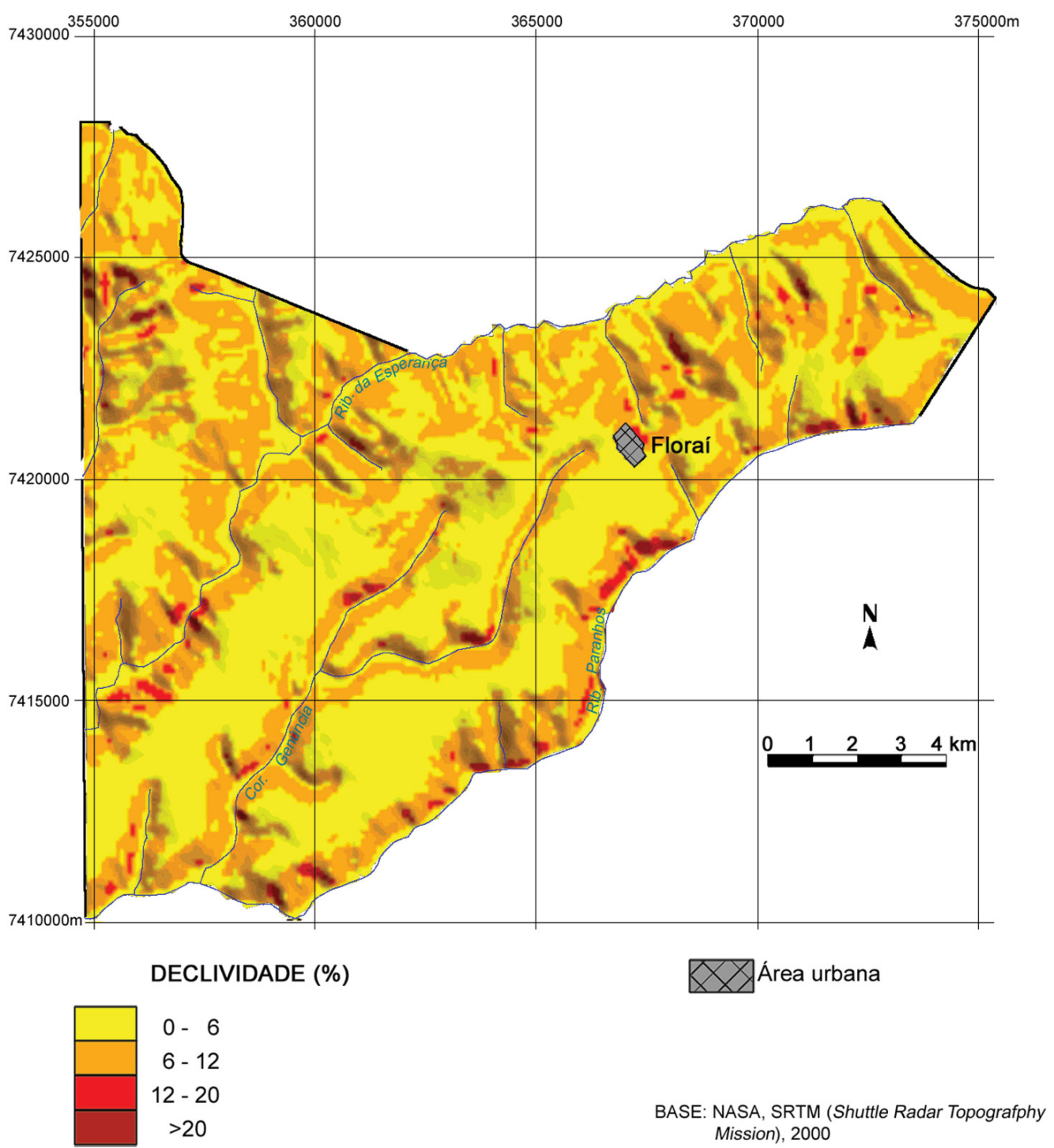

Figura 2 - Mapa de declividades do município de Floraí

Essa diversidade do substrato geológico e do relevo se reflete também em diversidade de tipos de solos e na organização da cobertura pedológica, contrapondo solos de textura média, Latossolos e Argissolos, dominantes nas áreas de ocorrência da Formação Caiuá, com Latossolos e Nitossolos de caráter férrico (conteúdo elevado de óxidos de ferro) e de textura argilosa a muito argilosa presentes nas áreas sustentadas pelo basalto (Figura 3). Na zona de contato arenito/basalto, os Latossolos gradualmente se enriquecem em argila em direção às áreas topograficamente mais baixas e de ocorrência das rochas vulcânicas sem, entretanto, adquirir o caráter férrico. Correspondem ao Latossolos Vermelhos, textura argilosa, no mapa da Figura 3. Esses solos são genericamente designados pelos agricultores como Terra Mista. Variações similares aparecem associadas à ocorrência das manchas de depósitos sedimentares coluviais que ocasionalmente recobrem os basaltos. Também são encontrados no município pequenos setores isolados, não mapeáveis na escala do mapa apresentado, 
de Neossolos Quartzarênicos e Neossolos Litólicos. Os primeiros ocorrem preferencialmente em áreas de cabeceira, sobre a Formação Caiuá, e os segundos são mais frequentes sobre o basalto.

Essas características fisícas, associadas aos tipos de uso da terra praticados, levaram Andrade (2005) ao reconhecimento de três unidades de paisagem no território municipal de Floraí (Figura 4): Unidade 1, ou Platô de Floraí; Unidade 2, ou Platô de Nova Bilac e Unidade 3, ou Compartimento de Genúncia. De acordo com o autor "a análise integrada desses elementos permitiu o reconhecimento de diferentes unidades de paisagem no território municipal de Floraí, caracterizadas por estruturas geoecológicas e socioeconômicas particulares" (ANDRADE, 2005, p. 53).

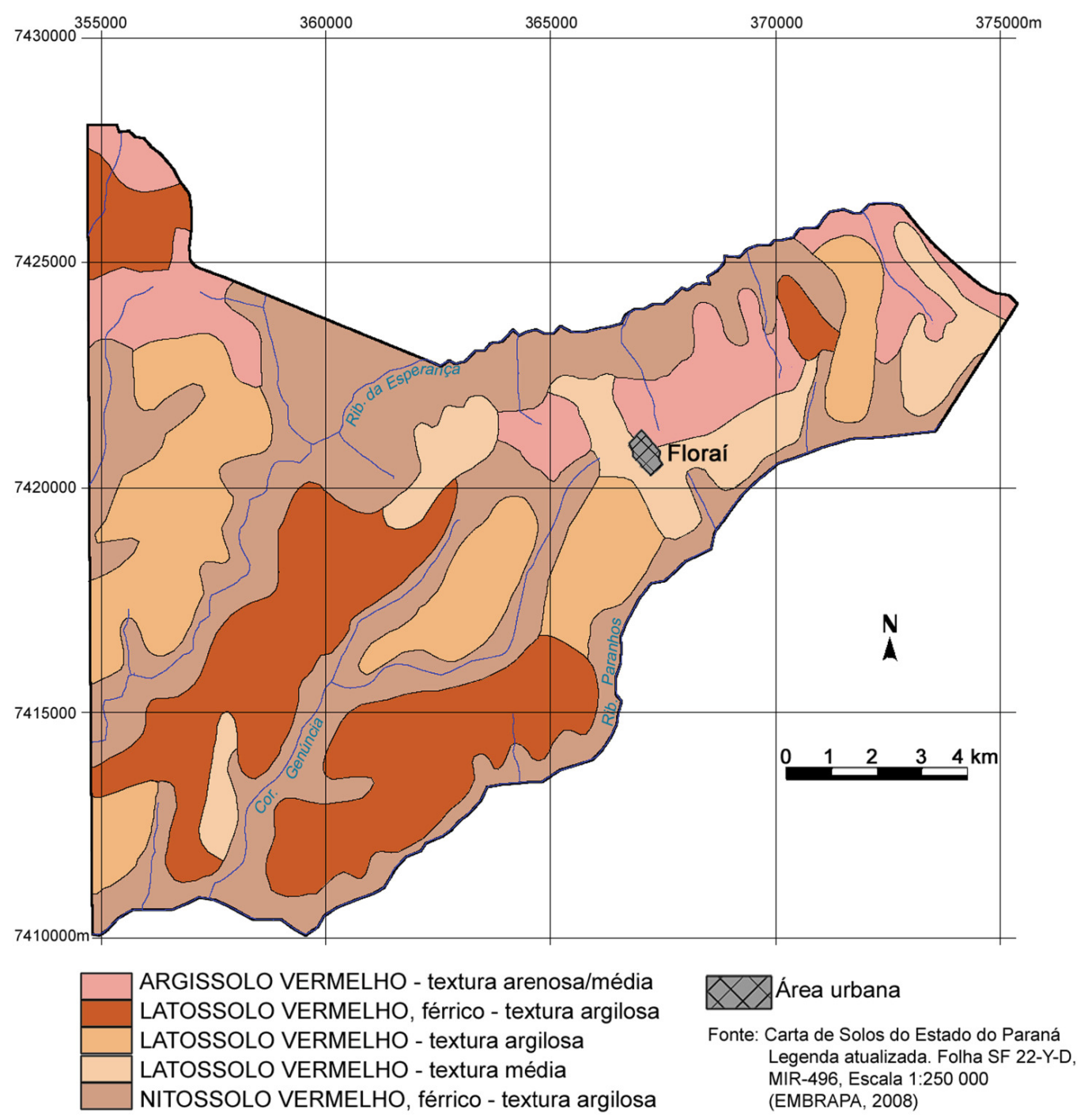

Figura 3 - Mapa de solos do município de Floraí (adaptado de EMBRAPA, 2008)

Em linhas gerais, as três unidades de paisagem, ou compartimentos, apresentam características que as diferenciam entre si, daí o termo "particulares" utilizado por Andrade.

A unidade 1, ou Platô de Floraí, situa-se na porção nordeste, onde se localiza a sede do município. Corresponde a um setor de interflúvio entre os ribeirões Esperança e Paranhos, alinhados na direção NE-SW. No topo do interflúvio as altitudes variam entre 460 e 560 metros, caindo entre 340 e 380 metros nos fundos dos vales.

Na maior parte desse compartimento domina como substrato geológico a Formação Caiuá, registrando-se, contudo, a ocorrência do basalto da Formação Serra Geral nos setores de baixa vertente e fundos de vale. Essa composição e distribuição do substrato geológico aparecem marcadas 
tanto na morfologia das vertentes, acentuadas por rupturas nas zonas de contato arenito/basalto (em torno de 400 metros de atitude) quanto nos tipos de solo que ocorrem ao longo das vertentes.

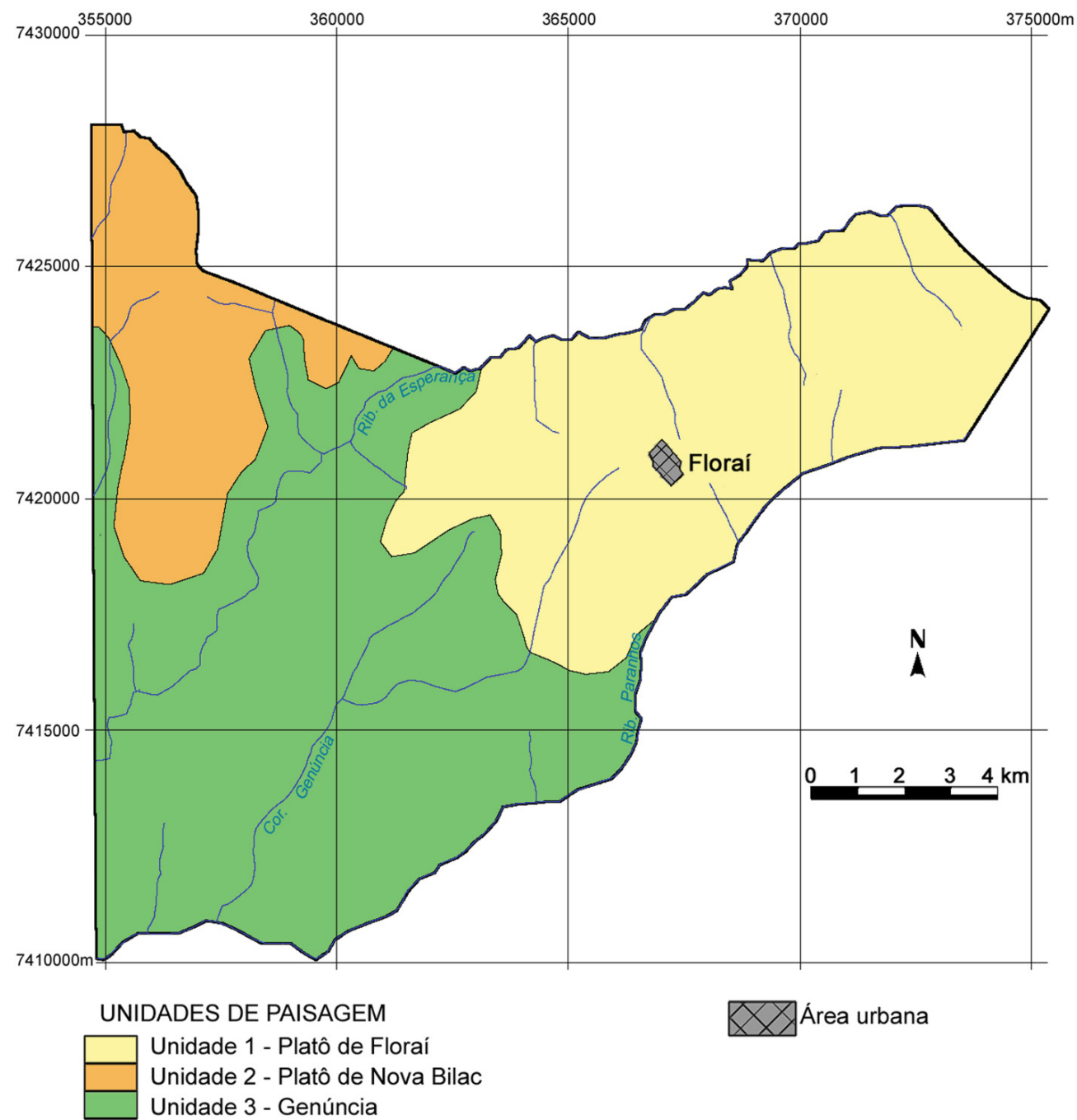

Figura 4 - Unidades de paisagem do Município de Floraí, conforme Andrade (2005)

No compartimento Platô de Floraí se destaca uma associação de solos caracterizada pela ocorrência do Latossolo Vermelho de textura média no topo e alta vertente, seguido do Argissolo Vermelho-Amarelo de textura média nos segmentos de média alta até a baixa vertente, derivados do arenito da Formação Caiuá. Na baixa vertente aparecem os Nitossolos Vermelhos associados à ocorrência do basalto.

A ocupação dos solos nesta unidade de paisagem vem passando por um processo de mudança, principalmente em função do avanço das lavouras de soja sobre a área de ocorrência do arenito. Até o ano 2000, a área era ocupada por pastagens plantadas e em alguns setores por lavouras de amoreiras tendo em vista a sericicultura, por lavouras de milho, mandioca, café e feijão, atividades características de pequenas propriedades. Após esse ano, com o fomento das lavouras mecanizadas, principalmente de soja sobre $\mathrm{o}$ arenito, as pequenas lavouras familiares passaram a perder espaço, sendo incorporadas às propriedades maiores. A cultura da laranja vem, também, se expandindo nessa unidade. Assim, a concentração fundiária e a agricultura empresarial contribuem para alterar a paisagem da Unidade 1. 
A unidade 2, ou Platô de Nova Bilac, está situada na porção norte do município. Este compartimento destaca-se pela topografia apresentando declividades mais acentuadas que a Unidade 1, cabeceiras em anfiteatros arredondados, pouco marcados e vales em berço. No que se refere à morfologia, as vertentes são convexas no topo, passando na sua porção intermediária a côncavoconvexa, formando patamares mais extensos do que aqueles observados no Platô de Floraí. No que se refere à cobertura pedológica, a área apresenta uma grande diversidade de tipos de solos. Distintamente do Platô de Floraí, a maior parte do setor mais elevado dessa unidade (mais entalhada, com morfologia de pequenas colinas) é recoberta em grande parte por Argissolos Vermelhos. Nos setores de topo menos entalhados e mais baixos aparece o Latossolo Vermelho de textura argilosa (a Terra Mista). Nos patamares, sobre o basalto, predomina o Nitossolo Vermelho. É comum, também, a ocorrência localizada de manchas de Neossolos Quartzarênicos hidromórficos no entorno de cabeceiras de drenagem em anfiteatros.

No que se refere ao uso econômico, as lavouras de soja competem com as lavouras de cana, implantadas mais recentemente no Platô de Nova Bilac. Até o ano 2000, a área era ocupada por pastagens associadas à pecuária de corte nas propriedades maiores e pela sericicultura, viticultura, além de lavouras de café, milho, feijão e mandioca, nas pequenas propriedades.

A Unidade 3, ou Compartimento de Genúncia, está situada na porção centro-sul do município e, como característica principal, localiza-se integralmente sobre o basalto da Formação Serra Geral. Sua topografia é marcada por colinas amplas entalhadas pelos ribeirões Esperança, Paranhos (trechos médios e inferiores) e Genúncia, com altitudes variando entre 340 e 380 metros. Dominam nessa unidade de paisagem, nos setores de topo e alta a média vertentes, o Latossolo Vermelho Eutroférrico, sendo que a partir da média encosta aparece o Nitossolo Vermelho Eutroférrico, ambos de textura argilosa, podendo ocorrer na baixa vertente o Neossolo Litólico.

No compartimento de Genúncia, até os anos 1970 a ocupação do solo teve o predomínio das lavouras de café; com a crise do café, passaram a predominar as lavouras temporárias mecanizadas, com destaque para a soja, o milho e o trigo. Mais recentemente, as lavouras de cana-de-açúcar começaram a avançar, impulsionadas pela instalação de uma usina de álcool em São Carlos do Ivaí, município vizinho.

É nesse compartimento que a agricultura de caráter empresarial está instalada. É nessa paisagem rural que se observa as instalações de silos em propriedades particulares e a instalação de grandes galpões para abrigo de maquinário pesado empregado nas lavouras.

\section{CONSIDERAÇÕES FINAIS}

Difícil encontrar um espaço melhor do que o Noroeste do Paraná para se explicar o significado do termo paisagem e sua evolução. A região oferece todos os exemplos possíveis e imagináveis que ajudam a entender a extensão do termo. No contexto do espaço regional, o município de Floraí, igualmente explorado no presente trabalho, também contribui para o enriquecimento do estudo de paisagem, pela forma como foi ocupado e pelas transformações que sofreu no decorrer de um lapso de tempo.

Região e município foram ocupados em função das lavouras de café, dando origem a uma paisagem agrária que tinha o homem habitando no campo, transformado em espaço de produção e em espaço de moradia. Como num passe de mágica, o café desaparece e com ele uma paisagem típica. No lugar, outra ou outras paisagens surgem e se sucedem umas às outras, construindo mosaicos que enriquecem o enfoque paisagístico, tornando a paisagem representativa de algo dinâmico e versátil. No lugar do café e das lavouras de subsistência, as lavouras mecanizadas de soja, trigo e milho e as pastagens plantadas para sustentar uma pecuária de corte; no lugar da bipolaridade na nova forma de uso do solo (lavouras mecanizadas de um lado, pastagens plantadas do outro), a concorrência das lavouras de cana-de-açúcar. Cada alteração constrói um tipo de paisagem e destrói outro tipo de paisagem. 
Desse modo, ora a paisagem aparece uniformizada por um tipo de uso e um produto, quando este é indiferente às variações da maior parte dos atributos físicos e estrutura geoecológica, como foi com o café no passado e é atualmente com a cana-de-açúcar; ora a paisagem surge diversificada, marcada por diferentes usos e produtos, esses mais sensíveis às variações dos atributos físicos, como as características dos solos e à sua capacidade de produção e vulnerabilidade em face das práticas aplicadas, como ocorreu quando da implantação do sistema soja/trigo e/ou soja/milho na região, criando áreas preferenciais para o desenvolvimento dessas atividades. No desenrolar dessas transformações, em cada uma das fases de evolução da paisagem, a potencialidade e o valor da terra também se modificam. Assim, a capacidade de suporte e de produção para os usos e atividades mais rentáveis economicamente em um determinado período criam espaços mais valorizados economicamente do que outros no interior do território municipal, influenciando também as transformações tanto da estrutura fundiária quanto das relações homem/campo.

$\mathrm{Na}$ região, com as mudanças, o homem perde seu endereço como morador do campo e sua identidade como agricultor que tira da terra, com próprio trabalho, o fruto da sua sustentação e de sua prosperidade econômica. Agora quem explora a terra é a usina de álcool e o usineiro é o novo ator social.

As mudanças são rápidas e para serem percebidas é que foi necessário resgatar a história da ocupação e demonstrar os fatos das transformações recentes. Por outro lado, com o dinamismo das transformações regionais, é facilitado o entendimento do significado do termo paisagem. $\mathrm{O}$ conceito de paisagem explicado pela dinâmica de um espaço. Enfim, o que poderia ser considerado um casamento perfeito.

\section{REFERÊNCIA BIBLIOGRÁFICA}

ANDRADE, J.A. As unidades de paisagem e os sistemas de produção agrícola no município de Floraí-PR. Maringá: Universidade Estadual de Maringá/Programa de Pós-Graduação em Geografia, 2005 (Dissertação de Mestrado em Geografia).

BOLÓS, M. De. Manual de Ciencia del Paisaje: Teoria, Métodos y Aplicaciones. Barcelona: Masson, 1992. CMNP - Companhia Melhoramentos Norte Do Paraná. Colonização e Desenvolvimento do Norte do Paraná. São Paulo, 1975 (edição comemorativa do cinquentenário da CMNP).

CPTI - Cooperativa de Serviços, Pesquisas Tecnológicas e Industriais. Relatório de Situação dos Recursos Hídricos da UGRHI do Pontal do Paranapanema. São Paulo: CPTI, 2000. Disponível em: http://www. sigrh.sp.gov > Acesso em 4 abril 2011.

DINIZ, J. A. F. Geografia da Agricultura. São Paulo: Difel, 1986.

CHRISTOFOLETTI, A. A geografia física no estudo das mudanças ambientais. In: BECKER, B.K. (Org.) Geografia e Meio Ambiente no Brasil. São Paulo. HUCITEC. P. 334-345, 1995

EMATER - Empresa Paranaense de Assistência Técnica e Extensão Rural. Perfil da Realidade Agrícola de 2003/2004. Floraí: EMATER, 2004.

EMBRAPA - Empresa Brasileira de Pesquisa Agropecuária. Carta de Solos do Estado do Paraná. Legenda Atualizada. Folha MIR-496. Escala 1:250.000. 2008

MELO, D. R. Geossistemas: Sistemas Territoriais Naturais. Belo Horizonte, 1995. Disponível em: < http:// ivairr.sites.uol.com.br/dirce.htm $>$ Acesso em agosto/2011

MINEROPAR - Minerais do Paraná. Carta Geomorfológica Londrina. Curitiba. 2006a. 1 mapa. Color. Escala 1:250.000. Disponível em: <http://www.itcg.pr.gov.br/modules/conteudo/conteudo.php?conteudo=55 $>$ Acesso em: 10 abril 2011.

MINEROPAR - Minerais do Paraná. Mapa Geológico. Folha de Londrina. Curitiba. 2006b. 1 mapa. Color. Escala 1:250.000. Disponível em: < http://www.mineropar.pr.gov.br/arquivos/File/2_Geral/Geologia/ PDF_Mapas_Geo_250000/Londrina.PDF > Acesso em: 4 abril 2011 
MINEROPAR - Minerais do Paraná. Carta Geomorfológica Londrina. Curitiba. 2006a. 1 mapa. Color. Escala 1:250.000. Disponível em: < http://www.itcg.pr.gov.br/modules/conteudo/conteudo.php?conteudo=55 $>$ Acesso em: 10 abril 2011.

SANTOS, Milton. A natureza do espaço. São Paulo: EDUSP, 2004.

SOTCHAVA, V. B. Définition de quelques notions et termes de Géographie Physique. Dork1: Institute de Géographie de la Sibérie et Extrême Orient, n. 3, p.94-117, 1962.

Trabalho enviado em janeiro de 2013 Trabalho aceito em fevereiro de 2013 